\title{
Safety of online surgical training resources
}

\section{Michael Edwards*}

Friarage Hospital, Northallerton, North Yorkshire, DL6 1JG, UK

${ }^{*}$ Corresponding author at: Friarage Hospital, Northallerton, North Yorkshire, DL6 1JG, UK.

Email: michaeledwardsok@btinternet.com

Date accepted for publication: 16 July 2020

\section{Abstract}

Online surgical training resources should provide the trainee with unlimited, fault-free information. A preliminary investigation explored the standards of quantity, quality and safety of information provided in a sample of online training resources, describing wide-bore chest drain insertion. They were examined for information for a single essential step: the length of the skin incision. Twenty-five online resources were identified. Five failed to mention skin incision length at all. Four others gave unhelpful information. Four gave incorrect information. Eleven gave unsubstantiated numerical information that would probably lead to too short or, in one resource, to too long an incision. The online training resources included poor quality surgical information, with deficiencies and disagreements in the information given on skin incision length. Urgent correction of low quality and unsafe surgical information is recommended. In comparison, the MHDOS (Masterscript High Detail Operating System) website provides a highly detailed training resource correctly recommending a skin incision length that was half the circumference of the surgeon's forefinger and includes "what ifs" and evidence. Raising the standard of information available online could be achieved by linking the information from the high to the low detail resources. This could lead to better surgical safety standards worldwide.

Keywords: surgical education; websites; quality control; simulation; safety standards; LocSSIP

\section{Introduction}

The internet offers the opportunity to provide highly detailed operative information to the surgical community worldwide. This could comprise all the information that expert surgeons have at their fingertips, including evidence and guidance on how to proceed should different scenarios arise ("what ifs"). Online training resources should include complete information, avoiding errors or insufficiently detailed information that could mislead the surgical trainee and increase the risk of serious harm or even death of patients. ${ }^{1}$

At the time of writing, I am not aware of any quality assessment of online surgical resources. As a surgeon with wide experience of oesophageal surgery, I am familiar with the dangers of wide-bore chest drainage. The National Patient Safety Agency reported 12 deaths and 25 cases of serious harm from chest drain insertion in England and Wales between 2005 and 2008. ${ }^{2}$ Paradoxically, this procedure is judged to be a minor procedure by a leading medical insurance company. ${ }^{3}$

I am editor of an online resource, MHDOS (Masterscript High Detail Operating System), aiming to detail all the information that an expert handles when operating. ${ }^{4}$ This system includes all the 19 checks and safety standards present on the World Health Organization's surgical safety check list, created by Gawande and colleagues, that apply universally to any surgical procedure. ${ }^{5}$ The checks are confined to pre- and post-operative information. The WHO checklist lacks any procedure-specific per-operative information, but MHDOS scripts provide all this in great detail. The information is structured into categories such as what ifs, evidence and when to call for assistance. I was interested to investigate what other information is available online and to assess its quality.

This Editorial aims to explore the standards of quantity, quality and safety of information provided on a sample of online resources describing wide-bore chest drain insertion. I focused on one step in the procedure: the length of the skin incision. This may appear to be of trivial importance, but in fact there are many pitfalls for the unwary relating to this step of the procedure. It was not possible to identify a recognized standard for incision length for wide-bore chest drain insertion in the literature. Indeed, some of the resources examined in this Editorial have been published 
by organizations one might look to for such guidance, but no such standard is mentioned. However, the evidence for the size of incision used by MHDOS comes from basic geometry.

\section{Wide-bore chest drain insertion}

If we assume that the skin incision for insertion of a widebore chest drain needs to be precisely long enough to allow the surgeon to insert a forefinger into the pleural space (to explore the space to exclude adhesions), then the circumference of the opened up incision must be the same as the circumference of the base of the finger (Fig. 1). The linear skin incision, having two sides, opens to an $\mathrm{O}$ shape with a circumference double that of the original incision. Therefore, for the skin incision to match the finger circumference, it must be half the circumference of the finger. Readers can verify this by measuring the circumference of the base of their forefinger and making an incision half that size in a piece of cloth or skin, simulated or real.

The size of the drain tube is measured on the French Charrière gauge, after its French inventor (also known as F, Fr, or Ch gauge). ${ }^{6}$ The French gauge size is three times the diameter of the tube in millimetres and therefore slightly smaller than the circumference of the tube in millimetres (which would be $\pi$ or 3.14 times the diameter). To re-iterate, French gauge size is not the diameter of the tube in millimetres. So a $28 \mathrm{~F}$ chest drain has a circumference of just under $28 \mathrm{~mm}$. Its diameter is only about a third of that of the surgeon's finger. Therefore, the diameter of the drain tube does not play a part in the calculation of the length of the skin incision.

In addition, today's surgical trainee is unlikely to know the circumference of their forefinger or be able to mark a precise length on the skin (say $4 \mathrm{~cm}$ ). ${ }^{7}$ To avoid errors, trainees should be instructed to use a ruler to make these measurements accurately.

Also, the trainee needs to be able to anticipate and avoid errors (i.e. be aware of the what ifs). For example, what if the skin incision is too short? The finger may not reach inside the pleural cavity, with life-threatening delays while the surgeon struggles to find the cause and eventually to enlarge the incision. ${ }^{8}$ What if the incision is too long? Poor wound closure may lead to leakage of infected liquids, contaminating the patient's clothing and bedding. Contamination from the patient's surroundings may infect the pleural space retrogradely around the tube. ${ }^{9}$ The correct length of the skin incision will vary according to the circumference of the surgeon's forefinger.

\section{Online search and findings}

Google and YouTube were searched using the search term 'technique for chest drain'. For a preliminary investigation, this was expected to provide an adequate amount of information for analysis. This search method was preferred to conventional database searching, because a novice would

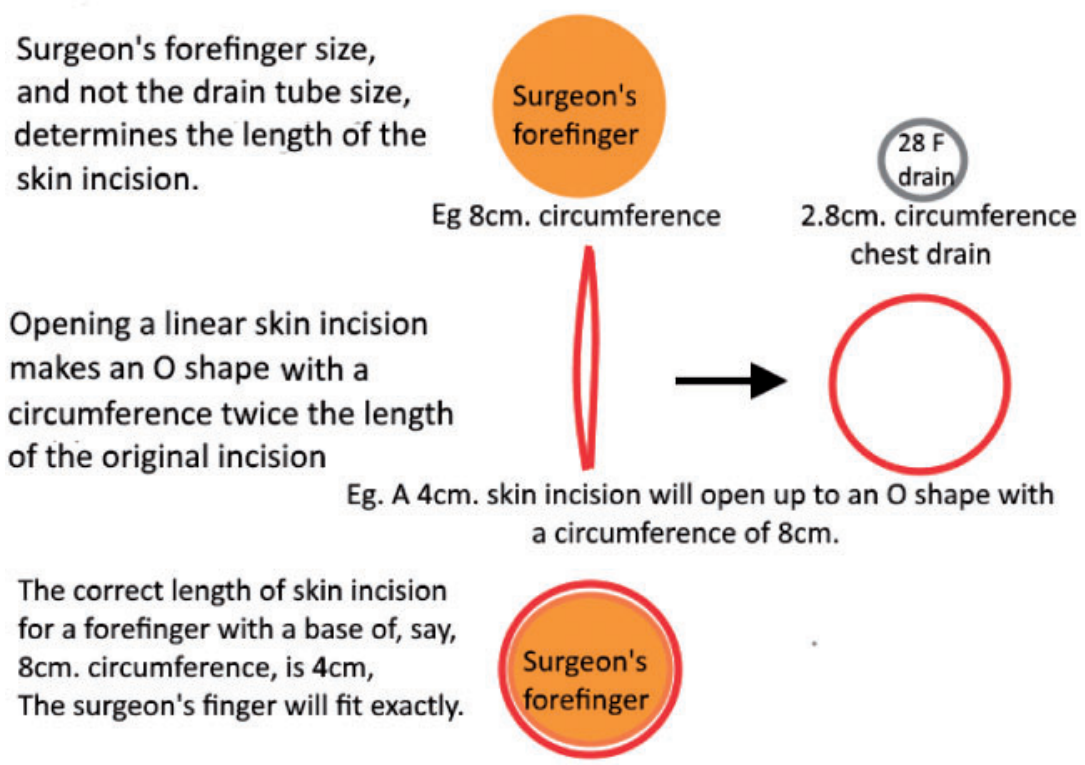

Figure 1. Correct length of a skin incision for a $28 \mathrm{~F}$ wide-bore chest drain. 
conventionally seek information using these sources first. For each online resource, I examined the information given regarding how to make an incision during the procedure for inserting a chest drain, any data on the online resource/views/viewers, country of origin, name of the organization/author, etc.

Twenty-five online resources ${ }^{8,10-34}$ describing wide-bore chest drainage were identified and sorted according to the increasing amount and quality of information. Of these, 12 were video based and 10 were text based. Two others were Local Safety Standards for Invasive Procedures (LocSSIPs). LocSSIPs are derivatives of the WHO Surgical Safety Checklist and may lack per-operative information. ${ }^{12,13}$ Two were computer-generated simulations: one containing unhelpful information and the other a range of incision lengths that would probably be too short. ${ }^{14,29}$ The number of views of the online resources recorded from the time of being first uploaded onto the internet until January 2019 were examined. Eleven online resources, all from YouTube, had 2,208,357 views (mean, 200,759). The number of views from other resources was not available.

Twenty of the resources correctly recommended exploring the pleural space with a finger. Five resources did not record whether the pleural space should be explored or not. Five resources did not mention skin incision length at all and four gave unhelpful information (Table 1). Four gave incorrect information (Table 2). Twelve suggested incision lengths from 1 to $5 \mathrm{~cm}$ (Fig. 2). There was no evidence of how they had been calculated. All gave information that would probably lead to too short an incision, ${ }^{22-32}$ except for one that would probably be too long. ${ }^{33}$ There was no information about what ifs. In MHDOS, the incision length is correctly described as half the circumference of the surgeon's forefinger, plus two what ifs. None of the descriptions, except for MHDOS, contained a satisfactory amount of clear, comprehensive and accurate information.

I am not aware of any other studies assessing the quality of operative information available online. In view of the large amount of time, expenditure and effort required to produce such resources, the outcomes are disappointing. This Editorial highlights a multitude of deficiencies in the online information on the procedure. Focusing on just one step within this procedure has produced ample information for a useful preliminary report. If the information surrounding any step of a surgical procedure is incomplete, obscure, imprecise, contradictory or incorrect, the consequences can be very serious for the patient. All such deficiencies were present among the online resources examined. Ideally, there should be a large amount of agreement among expert surgical authors, but this is not the case. It is essential that instructions for trainees are written at the appropriate level to suit their abilities, limited previous experience and knowledge. The widely differing recommended skin incision lengths from 1 to $5 \mathrm{~cm}$ shows lack of precision. Recommending a skin incision that is virtually impossible to penetrate with a finger (e.g. $2 \mathrm{~cm}$ or less in ten of the online resources) is alarming.

Some readers may feel that if there is large amount of detail provided in a description of a procedure that this will cause the trainee to spend an unnecessary amount of time working through each step. However, if a trainee surgeon is equipped with all the expert information, they should be able to perform actions smoothly, without hesitation and without error. Just one small step in one procedure was examined, and it may not be possible to extrapolate this to form a view of the quality of the information as a whole provided in the online resources examined.

\section{Future solutions}

As a solution, all of these online resources could be improved by adding in more detailed information as provided on the MHDOS website or by providing links to this information. Although MHDOS appears well ahead of the other online resources for quantity and quality of information, it is premature to refer to it as a gold standard. MHDOS is a flexible system that can be expanded and

Table 1 Online resources with information about skin incision length that was absent or unhelpful

\begin{tabular}{lll}
\hline Information (number of resources) & Information provided & Reference \\
\hline Information was absent $(n=5)$ & None & $8,10-13$ \\
Information was unhelpful $(n=4)$ & 'Make an incision' & 14 \\
& 'The incision is made' & 15 \\
& 'Open the incision' & 16 \\
17 & 'Nice long incision' &
\end{tabular}


Table 2. Online resources with incorrect information about skin incision length

\begin{tabular}{|c|c|c|}
\hline Information (number of resources) & Information provided & Reference \\
\hline \multirow[t]{4}{*}{ Information was incorrect $(n=4)$} & $\begin{array}{l}\text { 'The incision for insertion of the chest drain should be similar } \\
\text { to the diameter of the tube being inserted.' }\end{array}$ & 18 \\
\hline & $\begin{array}{l}\text { 'Make a transverse incision through skin and superficial soft } \\
\text { tissues large enough to accommodate the drain you have } \\
\text { chosen.' }\end{array}$ & 19 \\
\hline & $\begin{array}{l}\text { 'Make an incision large enough to accommodate the chest } \\
\text { drain and allow adequate dissection.' }\end{array}$ & 20 \\
\hline & $\begin{array}{l}\text { 'Make the incision large enough not only for the chest drain } \\
\text { but also to accept the clamp for the dissection into the chest } \\
\text { cavity.' }\end{array}$ & 21 \\
\hline
\end{tabular}

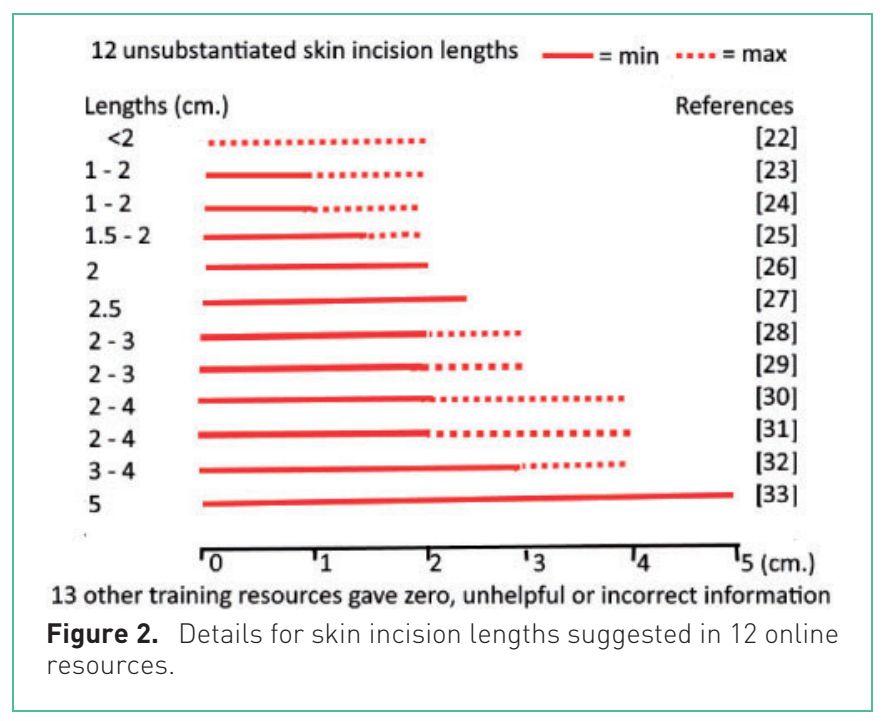

validated by external organizations, colleges, and practising surgeons. However, by adopting the MHDOS approach, many of these online resources could be improved.

To provide a clearer picture of the quality of operative information available online, future studies could focus on:

(1) examination of other components of the wide-bore chest drain procedure in the same online resources

(2) examination of the information given about other procedures in these same online resources

(3) investigation of what other resources are available covering other procedures, and an assessment of the quality of information they contain.

Furthermore, there is a need for supervision of future online resources and supervision of authors using quality control, quality assessment and quality assurance, which are in their infancy in surgery. ${ }^{35}$ This paper suggests that the question of quality control or accreditation of online information must be addressed. There is a need for an overarching organization that could apply quality control to all websites in the world. An accreditation system much stricter than ones used by the online authors here could be achieved easily by using the MHDOS information and structure. A means of error management in health care already exists from aviation and could be used here. ${ }^{36}$ MHDOS consists of comprehensive information categories (e.g. what ifs and evidence) that allow unprecedented documentation of highdetail information for any procedure. ${ }^{3,37}$ Research possibilities include developing the use of MHDOS to elicit highdetail operative information from other surgeons as described previously. ${ }^{38,39}$ MHDOS could be used at a hands-on level to identify why some centres have outstanding results and others have poor results.

\section{Conclusions}

None of the online resources looked at in this Editorial, including simulations and LocSSIPs, provided comprehensive, precise, reliable, correct and uncontradictory information on this single, but essential, step in one small operation, to the level provided by MHDOS. Gawande (personal communication, 2014) has stated that it was a very valuable way to progress beyond his WHO Safety Checklists, i.e. to fill the per-operative information gap. Encouraging surgeons to comment on scripts for different procedures would be a way to crowdsource expertise, leading to improved levels of surgical safety, aiming towards safety levels currently seen in the aviation sector. This preliminary investigation has shown clear and serious deficiencies in the quantity and quality of information describing one step in a small, but important surgical procedure in 25 online resources. Urgent corrective action can be taken using information from the MHDOS website. The structure of the information in this website can be applied to any surgical procedure to raise safety standards of surgery worldwide. 


\section{Acknowledgements}

We are most grateful to RocketMedical who kindly donated chest drain samples to assist in this study.

\section{Conflict of interest}

The author is the editor of MHDOS.info and author of MHDOS Chest Drain and MHDOS Aortic Aneurysm Grafting, but does not receive any financial or personal reward for this work.

\section{References}

1. Gawande AA, Zinner MJ, Studdert DM, Brennan AB. Analysis of errors reported by surgeons at three teaching hospitals. Surgery 2003; 133: 614-621. https://doi.org/10.1067/msy.2003.169.

2. Lamont T, Surkitt-Parr M, Scarpello J, Durand M, Hooper C, Maskell N. Insertion of chest drains: summary of a safety report from the National Patient Safety Agency. BMJ 2009; 339: b4923. https://doi.org/10.1136/bmj.b4923.

3. British United Provident Association. Insertion of a tube into pleural cavity. British United Provident Association Procedures T1240. Available from: https://codes.bupa.co. uk/procedures (accessed 4 July 2020).

4. Edwards MH. Masterscript High Detail Operating System (MHDOS) 2019. Available from: www.MHDOS.info (accessed 4 July 2020).

5. World Health Organization. WHO Surgical Safety Checklist. Available from: https://www.who.int/patientsafety/safesurgery/ checklist/en/ (accessed 4 July 2020).

6. French catheter sizes. Wikipedia. Available from: https://en. wikipedia.org/wiki/French_catheter_scale (accessed 4 July 2020).

7. Coughlan S. Surgery students losing dexterity to stitch patients. BBC News, 30 October 2018. Available from: https://www.bbc.co.uk/news/education-46019429 (accessed 4 July 2020).

8. MEDLEARN. Chest tube insertion. 8 March 2015. Available from: https://www.youtube.com/watch? $\mathrm{v}=\mathrm{mBI} 1 \mathrm{XE} 14 \mathrm{fDE} \& \mathrm{t}=2 \mathrm{~s}$ (accessed 4 July).

9. Corcoran JP, Psallidas I, Wrightson JM, Hallifax RJ, Rahman NM. Pleural procedural complications: prevention and management. J Thorac Dis 2015; 7: 1058-1067. https://doi.org10. 3978/j.issn.2072-1439.2015.04.42.

10. Snyder GE. Simulated chest tube. 25 November 2016. Available from: https://www.youtube.com/watch?v=rLA1 scnOcWQ (accessed 4 July).

11. Leeper R. Chest tube instructional video. 4 January 2017. Available from: https://www.youtube.com/watch?v=XaGI-z HQVBA\&t $=421$ s (accessed 4 July).

12. Examples of Local Safety Standards for Invasive Procedures. Guidelines for pleural procedures. NHS Improvement.
Available from: https://improvement.nhs.uk/resources/exam ples-local-safety-standards-invasive-procedures/ (accessed 4 July 2020).

13. Intensive Care Society. Safety checklists for invasive procedures. Available from: https://www.ics.ac.uk/ICS/Guidelines Standards/Checklists/ICS/GuidelinesAndStandards/CheckLists. aspx?hkey=5f25c8ee-a999-41e3-98e6-787bf1177a67 (accessed 4 July).

14. Touch Surgery. Basic skills: chest tube insertion. Available from: https://www.touchsurgery.com/simulations/chest-tubeinsertion-1 (accessed 4 July).

15. umemergencymed. Tube thoracostomy. 8 January 2012. Available from: https://www.youtube.com/watch?v=U618Jte 1Uk (accessed 4 July).

16. Doncaster and Basset Law Hospitals HNS Foundation Trust. Guidelines for the insertion and management of chest drains. Available from: https://www.dbth.nhs.uk/wp-content/uploads/ 2017/07/PAT-T-29-v.1-Chest-Drains-Guidance-incl-changes -TJN-review-date-extended.pdf (accessed 4 July).

17. EM:RAP Productions. Chest tube placement. 2 August 2016. Available from: https://www.youtube.com/watch?v=IdmMR 8JxmFo (accessed 4 July).

18. Laws D, Neville E, Duffy J; on behalf of the British Thoracic Society Pleural Disease Group. BTS guidelines for the insertion of a chest drain. Thorax 2003;58(Suppl II):ii53-ii59. https://doi.org/10.1136/thorax.58.suppl_2.ii53.

19. Royal Cornwall Hospitals NHS Trust. Insertion and management of chest drains clinical guideline V2.0. November 2019. Available from: https://doclibrary-rcht.cornwall.nhs.uk/Docum entsLibrary/RoyalCornwallHospitalsTrust/Clinical/Respiratory/ InsertionAndManagementOfChestDrainsClinicalGuideline.pdf (accessed 4 July 2020).

20. Mittapalli D, Bosanquet DC, Mcelnay PJ, Harries R, Wild J. Foundation skills in surgery: handbook. London: Association of Surgeons in Training, 2016.

21. Weldon C for OPENPediatrics. Chest tube placement. 17 February 2016. Available from: https://www.youtube.com/ watch?v=_6sFa79u6FQ (accessed 4 July 2020).

22. Evans S. Intrapleural chest drains - insertion and management. NHS Salisbury NHS Foundation Trust. Available from: https://viewer.microguide.global/SALIS/CLINICAL\#con tent,a151f0c0-cd68-4ce6-92cb-0ad8b2e04978.

23. Keira T, Demery K. Chest tube insertion part 1/2. 13 July 2012. Available from: https://www.youtube.com/watch?v= 424M8L5Z_EQ (accessed 4 July).

24. Nickson C. Life in the fast lane. intercostal catheter. 24 April 2019. Alfred ICU in Melbourne, Australia. Available from: https://litfl.com/intercostal-catheter-chest-drain/ (accessed 4 July 2020).

25. Dev SP, Nascimiento D, Simone C, Chien V. Performing medical procedures: chest-tube insertion. New England Journal of 
Medicine, 13 April 2011. Available from: https://www.youtube. $\mathrm{com} /$ watch? $\mathrm{v}=\mathrm{kEc} 8 \mathrm{fn} 6$ ownc\&t $=5 \mathrm{~s}$ (accessed 4 July).

26. Gareeboo S, Singh S. Tube thoracostomy: how to insert a chest drain. Br J Hosp Med 2006; 67(Suppl 1). https://doi. org/10.12968/hmed.2006.67.Sup1.20339.

27. Gillaspie E, Blackmon S. Technique for chest tube insertion, 2017. Available from: https://www.ctsnet.org/article/techni que-chest-tube-insertion (accessed 4 July).

28. University of California San Diego. Standardized procedure: chest tube placement (adult). 28 September 2016. https://health.ucsd.edu/medinfo/medical-staff/application/Doc uments/SP65\%20Chest\%20Tube\%20Placement\%20(Adult).pdf (accessed 4 July).

29. William Lehman Injury Research Centre. Chest tube ATLS. 13 June 2014. Available from: https://www.youtube.com/watch? $\mathrm{v}=\mathrm{qR} 3$ VcueqBgc (accessed 4 July 2020).

30. Johns P. Chest tube insertion. 10 March 2009. Available from: https://www.youtube.com/watch? $\mathrm{v}=\mathrm{tSXQ7GR35E4}$ (accessed 4 July 2020).

31. Medics4Medics. Chest tube insertion for pneumothorax or hematothorax. 18 July 2016. Available from: https://www.youtube.com/watch?v=rhN_QgKvTkE\&t=7s (accessed 4 July 2020).

32. Cork Emergency Medicine. Chest drain insertion. Available from: www.emed.ie/Trauma/Chest/Chest_Drain.php (accessed 4 July 2020).
33. Oller C. DrER.tv. Chest tube placement. 21 November 2012. Available from: https://www.youtube.com/watch?v=xAepNE_DTQ (accessed 4 July 2020).

34. Edwards MH. MHDOS: Chest drain. Available from: https://www.MHDOS.info (accessed 4 July 2020).

35. Downey N. Ever made a mistake? The role of aviation-style error management in healthcare. J Surg Simul 2019; 6: 27-30. https://doi.org/10.1102/2051-7726.2019.0005.

36. Weyers S, Van Calenbergh S, Van Nieuwenhove Y, Mestdagh G, Coppens M, Bosteels J. Quality assessment in surgery: where do we stand now and where should we be heading? Gynecol Surg 2014; 11: 89-95. https://doi.org/10.1007/ s10397-014-0839-3.

37. Knox R, Edwards MH. Aortic aneurysm grafting: a Pantogen operative script. Available from: https://www.wikisurgery. com/images/2/2e/Aortic-aneurysm-graft-Operationscript.pdf (accessed 4 July 2020).

38. Edwards $\mathrm{MH}$, Coughlan J, Morar S. Eliciting and storing operative information from expert surgeons using surgical scripts: a content analysis study. Int J Surg 2007; 5: 267272. https://doi.org/10.1016/j.ijsu.2007.01.006.

39. Edwards $\mathrm{MH}$, Agha R, Coughlan J. Capturing intra-operative safety information using surgical wikis. Inform Health Soc Care 2013; 38: 120-131. https://doi.org/10.3109/17538157. 2012.705203. 